\title{
A CRIMINALIZAÇÃO DO NEGRO E DAS PERIFERIAS NA HISTÓRIA BRASILEIRA
}

\section{THE BLACK PERSON AND SUBURBS CRIMINALIZATION IN BRAZILIAN HISTORY}

\author{
Enio Walcácer de Oliveira Filho ${ }^{1}$
}

\begin{abstract}
Resumo
O presente artigo busca estudar a criminalização do negro no Brasil, como consequência do processo de colonização e escravidão operado no país à partir do Século XVI, fazendo um paralelo histórico entre o período de escravidão e o regime nazista estudado por Bauman, e a manutenção da segregação social e da seletividade operada pelo sistema penal no Brasil em face dos negros, como fator derivado desta (des)construção humana. Para tanto é feito no decurso deste artigo um estudo estatístico sobre a seletividade das mortes por arma de fogo no Brasil, e ainda sobre a segregação dos negros nas prisões brasileiras, em uma demonstração da operacionalização segmentada e direcionada a um grupo no que se pode determinar como uma tentativa de "branqueamento" por meio da violência na história brasileira.
\end{abstract}

Palavras-chave: Criminalização; Direito penal; Estigmatização; Eegro; Preconceito.

\begin{abstract}
This article seeks to study the criminalization of black people in Brazil as a result of the colonization process and the slavery operated in Brazil for from the sixteenth century, making a historical parallel between the period of slavery and the Nazi regime studied by Bauman, and the maintenance of social segregation and selectivity operated by the criminal justice system in Brazil in the face of black people as a factor derived from this human (de)construction. Will be already done a statistical study of the selectivity of deaths by firearms in Brazil, and also on the segregation of blacks in Brazilian prisons, seeking to demonstrate the selectivity of the instituted and shear forces in a process that will be working as an attempt to "bleaching "through violence in brazilian's history.
\end{abstract}

Keywords: Criminalization; Criminal law; Stigmatization; Black people; Prejudice.

\footnotetext{
${ }^{1}$ Mestre em Prestação Jurisdicional e Direitos Humanos, pós-graduado em Ciências Criminais e em Direito e Processo Administrativo, graduado em Comunicação Social e Direito, todos pela Universidade Federal do Tocantins. Coordenador de Iniciação Científica, Extensão e Pós-Graduação e titular da cadeira de Processo Penal na Faculdade Serra do Carmo - FASEC. Escritor das obras Constituição \& Inquisição (Lumen Júris) e A tutela penal das Modernas Biotecnologias (PerSe),bem como organizador de obras jurídicas. Servidor efetivo da Polícia Civil do Tocantins e colunista de jornais e sites jurídicos.
} 


\section{CONSIDERAÇÕES INICIAIS}

No presente texto o que se faz é uma reflexão acerca da criminalização do negro e das periferias brasileiras sob uma perspectiva dialético-histórica-material, em um estudo sobre a sociologia brasileira e a discriminação que se opera no país desde a colonização portuguesa. Fazendo um apanhado histórico, busca-se entender o processo de criminalização do negro no Brasil colônia, na sua instrumentalização, sua transformação em produto para o "desenvolvimento brasileiro" naquele período e as consequências históricas desta instrumentalização para o Brasil hodierno, questionando se realmente após a abolição da escravatura se efetivaram políticas de integração, ou se os negros foram mantidos na separação clássica entre a "casa grande" e "senzala" nos dias atuais.

Fazendo um comparativo entre as zonas periféricas, favelas e as antigas senzalas, apresentaremos a visão de que pouca coisa mudou desde a colônia portuguesa até o presente, fazendo com que se opere na atualidade um estado de direito diferenciado entre a "casa grande" e a "senzala" permitindo com isso uma criminalização dos negros e periféricos na sociedade brasileira, questão esta que redunda em ações tanto estatais quanto de poderes paralelos que estão levando à dizimação dos negros no país.

Para tanto fez-se um paralelo entre tais questionamentos e a obra de Zigmunt Bauman Modernidade e Holocausto, além de lançarmos mão de estudos antropológicos e históricos sobre a segregação racial no Brasil, mostrando-se ao final as consequências deletérias deste legado histórico para a criminalização de certas categorias de pessoas, seja pela origem ou mesmo pela posição sócio geográfica que estas ocupem na sociedade hodierna.

\section{A CRIAÇÃO DO ESTEREÓTIPO DO MAL}

Para que me pôr no tronco/ Para que me aleijar/ Eu juro a vosmecê / Que nunca vi Sinhá / Por que me faz tão mal / Com olhos tão azuis / Me benzo com o sinal / Da santa cruz... (BOSCO e BUARQUE, 2011, on line)

Na canção de Chico Buarque, em sua voz de lamento, uma história breve é contada, que mistura a malandragem do preto da senzala com a indiferença do branco senhor da Casa Grande. Uma das tantas histórias, das tantas formas de 
recontar a mesma trama da estigmatização e criação do que chamaremos aqui de "negro conceitual"2.

A história da criação da mitologia do "negro conceitual" no Brasil deve ser entendida à partir de sua descoberta e exploração como fonte de recursos pelos portugueses. Juntamente com a colonização iniciou-se no país um processo exploratório da mão de obra dos escravos negros, que então eram tratados e cambiados como animais, trazidos da África à partir de meados do século XVI em longas travessias que duravam em média 30 dias. O transporte em si já era algo aterrador - nus, acorrentados uns aos outros, com comida escassa, ausência de nutrientes e condições sanitárias que causava a morte de muitos antes de chegar ao Brasil.

Os escravos eram aqui mantidos como propriedade, tratados e comercializados como animais, sem direito algum, sendo explorados, justiçados, mortos sem a preocupação ou intervenção de ninguém. Os negros eram tratados como qualquer outro semovente sofrendo toda a sorte de ações que sofreria qualquer animal: eram trocados, castigados, vendidos, estuprados, mortos, sem a preocupação de serem ou não vidas humanas, seres dignos de direitos. (MOURA, 1989)

O justiçamento de escravos era na maioria das vezes feito na própria fazenda pelo seu senhor, havendo casos de negros enterrados vivos, jogados em caldeirões de água ou azeite fervendo, castrados, deformados além de castigos corriqueiros, como os aplicados com a palmatória, o açoite, o vira-mundo, os anjinhos. (MOURA, 1989, p. 18)

$\mathrm{Na}$ colônia, iniciava-se a instrumentalização do ser humano e a estigmatização de uma raça em duas possibilidades conceituais que referendavam a absurda exploração do negro: uma primeira, se se considerasse à época que os negros eram humanos, de que o homem poderia ser objetificado pelo homem; uma segunda, mais bestial ainda, de que os negros não eram homens e sim algum ser "inferior" que não deveria ser considerado parte da própria humanidade. É possível afirmar que a segunda premissa deve teve mais corpo à época, o que permitia o cometimento de toda sorte de atrocidades tendo em vista que a humanidade do ofensor estaria preservada, ao considerar o ofendido como animal, propriedade,

${ }^{2}$ Em alegoria direta ao estudo de Zigmunt Bauman no livro Modernidade e holocausto, quando fala do estigma criado em torno da figura do Judeu na história. 
portanto possível de toda a sorte de máculas em seu "adestramento" ou mesmo pelo mero prazer do seu proprietário.

Este "negro conceitual", jogado na senzala, nos campos de concentração brasileiros, como animais, era simples objeto, tido como "quase-homem", um bicho a ser domado, bestializado, instrumentalizado em prol do "desenvolvimento" que o homem branco europeu trazia às terras bárbaras e desprovidas de cultura da América do Sul.

Com a saída da senzala este negro ainda não tinha conseguido status de humanidade, tinha sido retirado das senzalas e jogado nas periferias, distanciados de sua terra natal, da África, alijados de suas raízes, cultura, famílias, em uma terra em que eram considerados como animais. Viram-se assim entregues à própria sorte nas periferias, nos guetos, distantes do homem branco ocidental dos centros de desenvolvimento da nação que se erguia.

Os guetos e periferias eram novas senzalas onde o ainda estigmatizado "negro conceitual", socialmente tido como animal recém emancipado dos campos de concentração, amontoavam-se sedentos de todas as necessidades, vendo-se às voltas em uma sociedade que continuava a excluí-los e na qual pareciam não participar, pelo menos como humanos. Naquele bioma distinto, às vezes vivendo em periferias, as vezes ainda reclusos em quilombos, viviam em uma outra realidade social, exprimindo ainda a desconfiança dos homens brancos ocidentais, nos cidadãos sociais inseridos. Era a continuação da estigmatização na manutenção do binário maniqueísmo do "nós" e "eles" entre os seres dignos e indignos da humanidade.

Aqueles indignos negros, amontoados como animais, exprimiam agora o medo em parte da sociedade que os via como animais selvagens, o bicho que vivia na senzala, preso por grilhões, agora emancipados. Criou-se e edificou-se o mito do homem branco civilizado do "eu cidadão" e do "ele animal". De um lado o homem branco que trouxe a civilização, o desenvolvimento para os nativos, a "ordem e progresso" imposta verticalmente de quem era detentor da sabedoria europeia necessária para o desenvolvimento dos nativos, e a extirpação de todos que fossem contra o projeto desenvolvimentista do Brasil. Do outro lado, no extremo, estava o negro, o "anti desenvolvimento" - o ser bestial, animal que sucumbe aos instintos inferiores, que pode facilmente roubar, estuprar, matar -, a antítese da ordem "branca", o negro era o próprio caos. Não importa a história, mas o mito criado em 
torno dela, "o preconceito contra negros e seus descendentes é oriundo de um contexto histórico de usurpação dos seus direitos e de uma construção paulatina de subjugação a partir da sua cor." (GUIMARÃES; CARDOSO; OLIVEIRA, 2015)

A escravidão foi a base a partir da qual se fundou uma civilização... $E$ ao fazê-lo, viabilizou um projeto excludente, em que o objetivo das elites é manter a diferença com relação ao restante da população". E para complementar, diz Luiz Felipe Alencastro: "A escravidão legou-nos uma insensibilidade, um descompromisso com a sorte da maioria que está na raiz da estratégia das classes sociais mais favorecidas, hoje, de se isolar, criar um mundo só para elas, onde a segurança está privatizada, a escola está privatizada e a saúde também. (GUIMARẨES; CARDOSO; OLIVEIRA, 2015)

As chacinas do branco, justificava-se, foram em prol de uma causa maior, de uma maior felicidade para um maior número de pessoas ${ }^{3}$, de uma utilidade para própria humanidade, permitia-se então o genocídio de índios, a exploração de escravos, tudo em nome do progresso, era, portanto, justificável.

Somado a estes estigmas formaram-se ainda os estigmas culturais, em que toda religião advinda de negros seria a própria encarnação do mal. Aliás, tudo que se originasse dos negros, já estigmatizados, símbolos da não humanidade, fora também marcado. O "negro conceitual" é um conjunto de atributos culturais, físicos, psicológicos ligados à cultura da senzala que depois se tornou gueto, periferia.

Segundo Sérgio Buarque de Holanda (1995, p. 56-57, grifos nossos) "os pretos e descendentes de pretos, esses continuavam relegados, ao menos em certos textos oficiais, a trabalhos de baixa reputação, os negro Jobs, que tanto degrada o indivíduo que os exerce, como sua geração", era o trabalho do negro também estigmatizado como indignos, inclusive sendo dissuadido o casamento entre os índios e negros e entre brancos e pretos, neste sentido o autor completa "em portaria de 6 de agosto de 1771, o vice-rei do Brasil mandou dar baixa ao posto de capitão-mor a um índio porque "se mostrara de tão baixos sentimentos que casou com uma preta, manchando seu sangue com esta aliança." É indiscutível a categoria menor relegada à raça negra na herança histórica e cultural do Brasil.

No âmbito religioso, as crenças da "Mama África" eram tidas como pagãs, artes ocultas ligadas ao demônio, no imaginário popular do homem branco, o detentor e impôs(i)tor da cultura (ir)real do Brasil miscigenado. Neste Brasil que nasceu miscigenado, quem impunha a cultura queria se dizer branco, mesmo sendo

\footnotetext{
${ }^{3}$ Em um paralelo à ideia propagada pelo funcionalista John Stuart Mill que entendia que seria uma opção justa o sacrifício de alguns para um maior benefício à maioria.
} 
mestiço, neste Brasil europeu inventado, o bem era tido como o cristão e o mal como o pagão.

O africano era tido como a essência do próprio demônio, crença fundamentada em mitos cristãos como o da "Maldição de Cam" para os negros, como dizia o Padre Antônio Vieira em seus Sermões (XI e XXVII) "a África é o inferno onde Deus se digna de retirar os condenados para, pelo purgatório da escravidão nas Américas, finalmente alcançarem o paraíso" dizendo ainda que "é melhor ser escravo no Brasil e salvar sua alma do que viver livre na África e perdela" (PASSOS, 2014)

Cita Walter Passos (2014, on line) que a escravidão e a mitologia do Mito de Cam para justifica-la foi:

[...] um processo planejado nas catedrais, nos concílios, no desejo de poder das igrejas católicas e protestantes e suas alianças com potências caucasianas, nas invasões através do mercantilismo, da escravidão, do colonialismo, do neocolonialismo, no capitalismo para roubar o continente africano e escravizar os seus filhos e filhas, atualmente tentando mantê-los desinformados e alheios da real liberdade com estigmas de amaldiçoados.

Tudo era circundado por um interesse mercantilista, a concentração de poder por meio da instrumentalização da própria humanidade,

a economia colonial latino-americana valeu-se da maior concentração de força de trabalho até então conhecida, para tornar possível a maior concentração de riqueza com que jamais contou qualquer civilização na história mundial. (PASSOS, 2014)

Neste Brasil colonial do bem e do mal, brotava a desigualdade, era um local onde, não diferente do que hoje acontece, "a abundância e a prosperidade eram simétricas à miséria da maioria da população, que vivia em estado de crônica desnutrição." (PASSOS, 2014)

Assim se formou, em breves palavras, a mitologia do "mal" no Brasil. $\mathrm{Na}$ simplicidade de conceitos, na atração pelo reducionismo do maniqueísmo, formouse uma classe dos inseridos socialmente, e uma classe dos excluídos.

Sócio espacialmente criou-se uma vinculação entre as periferias e regiões habitadas por seres "menos humanos", que buscam sempre a degeneração da nação, guetos do crime, local de pessoas não comprometidas, enquanto nos centros o mito inverso, de que ali estão as pessoas "comprometidas" pelo desenvolvimento e bem estar nacional, dignas e detentoras do poder e dos direitos. 


\title{
3. A DESUMANIZAÇÃO DE CATEGORIAS SOCIAIS: O PARALELO COM A EXPERIÊNCIA DO HOLOCAUSTO
}

Como fazer um paralelo da escravidão nas Américas com o Holocausto nazista? Existiria algum elo entre eles? Me perguntava isso e contestava a minha própria racionalidade quando lendo a obra de Zigmunt Bauman, Modernidade e Holocausto, me pegava criando paralelos entre um e outro.

Comecei a pesquisar pelos números de mortos, Bauman sobre isso disse que:

\begin{abstract}
embora os judeus não tenham sido a única população submetida a 'tratamento especial' pelo regime nazista (seis milhões de judeus estavam entre as mais de 20 milhões de pessoas aniquiladas ao mando de Hitler), só os judeus foram marcados para o extermínio, a destruição total, e não tinham lugar reservado na Nova Ordem que Hitler pretendia instaurar. (BAUMAN, 1998, p. 22)
\end{abstract}

No Brasil, segundo as fontes que consegui pesquisar, no período da escravidão foram trazidos para o Brasil, entre a segunda metade do século XVI e 1850, cerca de 3,9 milhões de escravos da África. Sobre este número devemos considerar que só chegavam ao Brasil cerca de $80 \%$ dos negros que embarcavam na origem, decorrente de toda sorte de doenças que acometiam os viajantes dos navios negreiros. Consideremos ainda que em 1850 a população do Brasil era de 3,5 milhões, sendo que destes 1,9 milhões eram negros, com expectativa de vida muito baixa e altas taxas de mortalidade. (CASTRO, 2015)

Estima-se que só em viagens de transporte de escravos tenham morrido cerca de 2,5 milhões durante o período (UCHOA, 2014), os outros viveram um certo tipo de "morte em vida", sendo tratados como animais nos campos de concentração chamados senzalas brasileiras, um número extremamente relevante considerandose a densidade demográfica do Brasil à época, muito menor que a alemã do Terceiro Reich.

Evidentemente que os números são distintos, mas proporcionalmente tinham como paralelo a barbaridade, e a desumanização de pessoas tidas como objetos, seja para um projeto de regulação social, ou hegemonia racial, seja para um projeto de enriquecimento mercantil.

Em ambos os projetos de "humanidade", de "civilização" - mesmo com consequências diversas e em momentos históricos diversos, tendo ainda motivos 
diferentes -, temos o que podemos expressar com as palavras de Richard L. Rubenstein da seguinte forma:

Civilização significa escravidão, guerras, exploração e campos de morte. Também significa higiene médica, elevadas ideias religiosas, belas artes e requintada música. É um erro imaginar que civilização e crueldade selvagem sejam antíteses... (apud BAUMAN, 1998, p. 28)

Tanto no período colonial no Brasil quanto na Alemanha Nazista, tínhamos um projeto civilizatório, utilitarista que implicava a utilização de pessoas como objetos em nome de um "projeto maior", consubstanciado por teorias religiosas, filosóficas, jurídicas que permitiram toda a sorte de crueldades sem considerar tais condutas como barbárie, pelo menos no período e para a população que perpetrava a dominação, sejam eles os alemães do Terceiro Reich, sejam para os "desbravadores" europeus do Brasil colônia, existiam causas legítimas e escusas "racionais" em diversos níveis para as atrocidades que foram cometidas.

O mesmo paralelo pode ser feito em diferente medida entre as máquinas de morte dos Judeus e as máquinas de comércio dos pretos no Brasil. Ambos foram consequências de seu tempo, representação máxima de um certo período da humanidade. Enquanto segundo Bauman (1998) "o assassinato em massa dos judeus da Europa pelos nazistas não foi apenas realização tecnológica de uma sociedade industrial, mas também sucesso de organização de uma sociedade burocrática", a instrumentalização e comercialização dos negros foi a soma da tecnologia mercantilista dos navios, oriunda da hegemonia exploratória europeia, e de uma sociedade em busca da ampliação da produção. Duas faces de um mesmo drama, separados pelo tempo mas unidas por um projeto de coisificação da humanidade.

\footnotetext{
O inconcluso processo civilizador ainda tem que ser concluído. Se a lição do assassinato em massa [e a escravização] de fato nos ensina algo é que a prevenção de semelhantes barbaridades evidentemente ainda requer mais esforços civilizadores. Não há nada nessa lição que lance dúvidas sobre a futura eficiência de tais esforços e seus resultados últimos. (BAUMAN, 1998, p. 32)
}

Se pensarmos, tanto na Alemanha nazista quanto no Brasil colonial, tivemos atrocidades cometidas por pessoas normais que, pensando em um projeto maior, amparadas emocionalmente e psicologicamente com uma justificativa de "modernidade" de um "bem maior social" criaram estruturas desumanizantes aberrantes. Eram pessoas "de bem", sujeitos que pretendiam um projeto de 
humanidade, certamente pacífico, mesmo que motivados por fatores diferentes. $\mathrm{Na}$ Alemanha por uma burocracia e uma descaracterização do indivíduo pela nação, no Brasil movido por uma vontade de ganho de capital, de ampliação da riqueza todas, contudo, instrumentalizadoras do ser humano por um projeto de humanidade, um antagonismo em níveis diversos onde se busca a humanidade pela desumanização de uma parcela dela.

Os alemães no Terceiro Reich não podem ser interpretados nas ações bárbaras que cometeram, nos termos descritos por Bauman (1998, p. 38) como "criminosos de nascença, sádicos, loucos, depravados sociais ou indivíduos de outra forma moralmente incompletos...", da mesma forma que não podem ser vistos assim os senhores de engenho, mercadores de escravos e Capitães do Mato no Brasil. São produtos de uma racionalidade de uma época que via todos os eventos como naturais, consequências colaterais do projeto desenvolvimentista da nação.

Interessante passagem de Bauman cita a exoneração da responsabilidade pessoal no Holocausto falando que: "Para compreender como foi possível essa cegueira moral estarrecedora, ajuda pensar nos operários da fábrica de armamentos que se alegram com a "suspensão do fechamento" de sua indústria graças a novas ordens grandiosas, ao mesmo tempo que lamentam os massacres mútuos de etíopes e eriteus: ou como é possível que a "queda nos preços das commodities" pode ser universalmente aclamada como uma notícia boa ao mesmo tempo que a "fome das crianças africanas" é lamentada de forma igualmente universal e sincera." (BAUMAN, 1998, p. 44)

É possível imaginar em paralelo o comerciante de escravos, sem presenciar a sorte do preto no Brasil, negociando a sua venda na África, desonerando sua consciência ao pensar na necessidade de seus ganhos para alimentar seus filhos. Ou ainda do capitão dos Navios Negreiros que deveria pensar que nada tinha com a escravidão, pois só transportava os "negros" ou mesmo dos Senhores de Engenho, que pensavam que melhor sorte tinham os negros em trabalhar que morrerem de fome nas ruas das cidades. A fragmentarização da instrumentalização permitia tal percepção, esse aumento "da distância física e/ou psíquica entre o ato e suas consequências produz mais do que a suspensão da inibição moral; anula o significado moral do ato e todo conflito entre padrão pessoal de decência moral e a imoralidade da conduta social do ato." (BAUMAN, 1998, p. 44) 
Como a lembrança de uma bondade de pessoas de boa vontade nos lembra John Lachs que:

\begin{abstract}
Sem o conhecimento direto das próprias ações, mesmo o melhor ser humano age num vazio moral: o reconhecimento abstrato do mal não é nem um guia confiável nem um motivo adequado... Não devemos [nos] surpreender com a imensa crueldade em grande parte não intencional de homens de boa vontade.... (apud BAUMAN, 1998, p. 45)
\end{abstract}

No nazismo se formavam os guetos sociais, áreas excluídas do direito, uma área onde era possível a atuação fora do direito legitimada pelo direito, na criação das vidas indignas, em uma zona de exceção, em um local onde tudo podia ser feito às margens do direito.

O Terceiro Reich findou-se por motivos externos, o Nazismo perdeu a sua guerra, o mundo então voltou-se contra tudo que havia sido perpetrado de barbaridades e, simbolicamente em Nuremberg puniu os principais líderes do regime. Os judeus formaram o que é o atual Estado de Israel, conseguiram a sua emancipação e a sua terra prometida, e é aqui que acabam os paralelos entre os regimes.

No Brasil o regime de exploração e coisificação dos negros deu-se em decorrência da Lei Áurea, fundada em pressões externas não tão condenatórias, já que grande parte do mundo "civilizado" havia também condenado a prática da escravidão. Este decreto criou um paradigma que teremos até os dias atuais, em que todos os problemas se resolvem com uma simples "canetada", sem debates e conscientização, um ato verticalizado de poder e não de transformação horizontal no pensamento social.

Como se fosse possível criou-se uma lei que aparentemente libertaria os negros, mas eles estavam aqui escravos dos estigmas, feridas sociais que perduram até os dias atuais no Brasil. Façamos um derradeiro paralelo ao nazismo e à problemática dos judeus:

Por séculos, o judeu foi alguém que viveu num bairro separado da cidade e usava uma roupa notavelmente típica [...] Relações que resistissem à formalização e à redução funcional eram de modo geral proibidas ou pelo menos desencorajadas." (BAUMAN, 1998, p. 56)

E da mesma forma se operou a segregação dos negros da sociedade dita civilizada. Operou-se primeiramente de forma muito mais abrupta, sendo os negros jogados em senzalas, galpões como bichos, desumanizados, sendo vistos socialmente pelos séculos da escravidão como animais, hostis, brutalizados e 
irracionais. Usavam roupas típicas, restos, características que seguiriam por muito tempo. Estigmatizados à época, hoje ainda mantém uma linguagem própria do gueto, uma linguagem marginal, uma música, dança, ginga, crença, de modo geral ainda estigmatizado, basta ver o rap das favelas, o funk "proibido", tal é hoje como era com a capoeira da senzala, as danças e as crenças, marginalizadas operando estigmas que se solidificaram e ainda permanecem.

Neste aspecto específico, Oracy Nogueira (apud ROCHA, 2007) aponta que no Brasil não existe a ocorrência de preconceito relacionado à raça ou ascendência (preconceito de origem) e sim um chamado preconceito de marca, constituído, por estimas marcadores de aparência, sendo que no Brasil, segundo Florestam Fernandes, a cor é usada no Brasil para uma imagem figurada da raça ou um "tropo para raça", na criação do que chamamos aqui de "o negro conceitual" no Brasil. (ROCHA, 2007, grifos nossos)

Já desumanizados por práticas e arbitrariedades históricas, buscou-se por meio da Lei Áurea uma libertação que serviu muito mais como símbolo vazio e justificativa à comunidade internacional do que para a efetiva libertação social dos negros. Com a lei, ao invés da libertação eles foram jogados à própria sorte e saindo da escravidão tiveram, para sobreviver, que ingressar em um sistema de semiescravidão trabalhando por parcos salários, morando ainda em guetos, favelas, casas que pouco mais condição tinham que nas senzalas. Aboliram as correntes de ferro e mantiveram-se as correntes sociais.

Desta forma o estigma da senzala manteve-se nas periferias formadas pelos negros pós-abolição da escravatura, ali as populações carregavam o estigma social da desumanização, em sentido muito aproximado ao que acontecia na senzala, ali não se aplicava os direitos que eram comuns aos insiders, ali era uma zona de exceção onde outro direito vigia, onde havia pessoas indignas que podiam a qualquer momento ser jogadas à ferros, no que veio a se transformar nos "troncos" da modernidade: os presídios.

\section{A MANUTENÇÃo dA CRIMINALIZAÇÃo do NEGRO E DA PERIFERIA NO BRASIL HODIERNO}

E por séculos seguindo as marcas, os estigmas, as cicatrizes dos grilhões da escravidão, permaneceu a ideia do "não civilizado" com a figura do negro, o 
marginal. Como estigma racial a cor da pele preta, como estigma sócio espacial zonas periféricas de alta concentração populacional e baixos índices de desenvolvimento humano. Nos centros das cidades continuaram as "Casas Grandes" e nas margens as "Senzalas", e em cada lugar continuaram alocadas, salvas exceções, as mesmas pessoas de outrora. "No senso comum, cidadãos negros são percebidos como potenciais perturbadores da ordem social, apesar da existência de estudos questionando a suposta maior contribuição dos negros para a criminalidade." (ADORNO, 1996)

As agências estatais do processo penal funcionam atualmente seguindo modelo estigmatizante, pressionadas por fatores históricos e culturais que levam a esta preconcepção falaciosa de que os pretos e periféricos são os que mais trazem riscos à sociedade. Há um efeito de suspensão do direito quando da atuação das agências responsáveis pela persecução penal quando atuando nas "senzalas modernas" ou quando diante do "negro conceitual". Com relação à estas pessoas estigmatizadas há uma seletividade de tratamento fora do âmbito dos direitos humanos na tentativa de conter, simbolicamente a criminalidade, no processo penal do espetáculo, com ferramentas como “...intimidação policial, as sanções punitivas e a maior severidade no tratamento dispensado àqueles que se encontram sob tutela e guarda nas prisões recaem preferencialmente sobre "os mais jovens, os mais pobres e os mais negros". (ADORNO, 1996)

Em decorrência de tais práticas, os negros continuam a morrer, continuam a ser presos, continuam a ser jogados à ferros. Mesmo com os constantes investimentos em segurança, parece que o benefício destes mantém-se apenas a beneficiar a "Casa Grande". Segundo pesquisas entre 2002 e 2008 o número de brancos assassinados no Brasil caiu 22,3\%, tendo crescido a morte de negros em $20 \%$. Em locais como Paraíba, são mortos $1.083 \%$ mais negros que brancos e na Bahia 439,8\% mais negros que brancos. (MENEZES, 2014)

O crescimento também do suicídio por pessoas pretas supera da mesma forma o suicídio em pessoas brancas, tendo aumentado no mesmo período em $51,3 \%$ enquanto para brancos houve um aumento de $8,6 \%$.

Mantém-se exatamente a mesma "racionalidade" do sistema social brasileiro que vigia desde o Brasil colônia ainda operante, mesmo que sub-repticiamente na atualidade, os negros ainda são segregados e os "habitantes da senzala" ainda não gozam do mesmo universo de direitos e garantias do morador da "Casa Grande". 
Sendo o foco do sistema penal, da atuação estatal, da violência punitiva, os "negros conceituais" que hoje abarcam não só os pretos, mas também os pardos que habitem as zonas de exclusão do direito penal, mantem-se o mito do "negro conceitual" como sendo uma pessoa, sob a ótica lombrosiana, voltada para a prática criminosa, e digo um mito exatamente por não haver sequer um estudo que mostre uma maior propensão do "negro conceitual" para o cometimento de crimes em relação ao branco.

Ao contrário, desde fins da década de 1920, alguns estudos americanos já haviam demonstrado o quanto preconceitos sociais e culturais, em particular o racismo, comprometiam a neutralidade dos julgamentos e a universalidade na aplicação das leis penais. Um dos estudos clássicos é o de Sellin (1928), que demonstrou a preferência seletiva das sanções penais para negros. (ADORNO, 1996)

Ou seja, o sistema retroalimenta o próprio mito, sendo que os estigmas históricos ligados ao "negro conceitual" fazem com que as ações estatais sejam seletivamente voltadas para estas pessoas e a aplicação da lei penal tenha uma tendência, conforme Sellin a ser aplicada de forma mais dura para pessoas com determinadas características sócio raciais: uma seletividade na aplicação de leis mais duras e na redução das garantias individuais para determinado tipo de pessoas de determinadas regiões geográficas.

Esta retroalimentação deste "negro conceitual" como o criminoso é feito punindo-se mais duramente negros, com ações estatais mais duras em periferias e consequentemente a divulgação na grande mídia destes casos criando a ideia de que, graças à esta superexposição midiática, o negro é o grande algoz da sociedade, o criminoso, uma ligação imaginária entre o "negro conceitual" e o criminoso na sociedade brasileira.

Segundo dados o "negro conceitual" é o maior alvo do sistema penal brasileiro, ocupando em 2012, quando a população carcerária brasileira era de mais de 515 mil presos, um percentual de 60,8\% nos presídios. A constatação que o relatório do Mapa do Encarceramento no Brasil (2015, on line) chegou é que a crescente população carcerária brasileira segue em paralelo com o crescente encarceramento dos negros, a estigmatização continua, uma forma de excluir os

\footnotetext{
${ }^{4}$ Nota do Mapa do Encarceramento interessante mostra o perfil do preso e a definição de negro para efeitos estatísticos: “Os dados coletados junto ao InfoPen foram recategorizados utilizando-se a categoria negros para a somatória dos indivíduos classificados como pretos e pardos, conforme o padrão censitário desenvolvido pelo Instituto Brasileiro de Geografia e Estatística (IBGE). Desta forma, as tabelas e os gráficos desta publicação seguem este padrão."
} 
negros da sociedade, em um processo de branqueamento social, a política republicada pós-colônia, a exclusão da condição de escravidão do negro, não mudou efetivamente a política de atuação (ou não atuação) do Estado com esta parcela da sociedade, na verdade:

a política republicana reforçou os esquemas de dominação herdados do período colonial. Diante disso, os negros tiveram dificuldade de se organizar na nova situação "a falta de preparação para a sua libertação a fim de que a assumisse com dignidade, apenas, trouxe-Ihes consequências inexequíveis tais como: sua marginalização, seu descrédito, sua despersonalização, levando-o a ter vergonha de si próprio. (BRASIL, 2015)

$\mathrm{Na}$ atualidade, com os números expressivos de vítimas de homicídio por arma de fogo que chegam no último relatório do Mapa da Violência a um número assustador de 42.416 mortes por arma de fogo só no ano de 2012. Destes 24.882 eram jovens de 15 a 29 anos (um percentual de mais de 58\%). Interessante agora colocar cor sobre os números. Os negros foram as maiores vítimas em decorrência de arma, representando um universo de $72,9 \%$ das vítimas ou como conclui o próprio relatório: "a vitimização negra foi de 142\%, nesse ano; morreram proporcionalmente e por AF 142\% mais negros que brancos: duas vezes e meia mais." Importante salientar que das mortes por arma de fogo de negros, entre as categorias de acidente, homicídio, suicídio e indeterminado, 95,56\% das mortes foram registradas como homicídios, um sistemático extermínio de negros que permanece no Brasil desde os tempos da escravidão. Com relação às vítimas jovens o quadro não difere, dentre os jovens vítimas de homicídios por arma de fogo os negros ocupam $76,72 \%$ das vítimas.

A conclusão numérica reafirma o embasamento histórico deste trabalho: permanece um sistema de higienização da raça negra no Brasil um sistema paralelo no tratamento com o negro, há mais violência contra uma determinada cor de pele, há um estigma de raça que permanece no Brasil hodierno.

\section{CONSIDERAÇÕES FINAIS}

O que se demonstra, por todo o exposto, é que permanece no tempo uma tentativa operada pelo sistema oficial, paralelo e social de "branqueamento" social, fatores complexos históricos e culturais que permitem que o negro seja o maior alvo dos crimes, vitimado, e seja o maior alvo do sistema penal. São os negros os que 
mais ocupam os presídios e as valas dos cemitérios, os que mais ocupam os guetos, os de menor poder aquisitivo e os que habitam as regiões periféricas, senzalas modernas, em que se opera um direito diferente, muito distante do direito positivado em nossa Constituição. O que existe ainda em nossa sociedade e precisa ser escancarado, debatido, retirado da cortina de fumaça, é um operante sistema estigmatizatório de preconceito contra os negros, que são vítimas tanto do crime quanto do sistema penal, e que podem ser considerados hoje ainda instrumentos, seja para o espetáculo que não raras vezes vira o nosso processo penal, ou pra o justiçamento de poderes paralelos nas periferias sociais. Negligenciar tais números, fatos e história é permitir a continuidade de um sistema de extermínio histórico operado sistemicamente tanto pelo poder constituído quanto pelos poderes paralelos em nosso Brasil.

É mais do que passada a hora de enfrentar este problema de frente, escancarar estas chagas sociais e talvez assim, combatendo de frente o que está escondido, possamos iniciar um processo de mudança e eliminar de vez as senzalas e os troncos da sociedade brasileira.

\section{REFERÊNCIAS}

ADORNO, Sérgio. Racismo, Criminalidade Violenta e Justiça Penal: Réus Brancos e Negros em Perspectiva Comparativa. Revista Estudos Históricos, FGV, v. 9, n. 18 (1996), p. 283-300. Disponível em: <

http://bibliotecadigital.fgv.br/ojs/index.php/reh/article/view/2034/1173> acesso em: 08/07/2015.

BAUMAN, Zigmunt. Modernidade e Holocausto. Rio de Janeiro: Zahar, 1998.

Brasil. Presidência da República. Secretaria Geral. Mapa do encarceramento: os jovens do Brasil / Secretaria-Geral da Presidência da República e Secretaria Nacional de Juventude. - Brasília : Presidência da República, 2015. Disponível em < http://www.pnud.org.br/arquivos/encarceramento_WEB.pdf>, acesso em 01/10/2015.

CASTRO, Leonardo. Escravidão e resistência no Brasil. Disponível em http://novahistorianet.blogspot.com.br/2009/01/escravido-e-resistncia-no-brasil.html acesso em: 07/07/2015.

GALEANO, Eduardo H. As veias abertas da América Latina. Porto Alegre: L\&PM, 2015.

HOLANDA, Sérgio Buarque de. Raízes do Brasil. São Paulo: Companhia das Letras, 1995. 
OLIVEIRA, Litiere; CARDOSO, Monique; GUIMARÃES, Mercedes. Escravidão, um passado para esquecer? On line, disponível em <

http://www.areliquia.com.br/artigos\%20anteriores/41escrav.htm> , acesso em: 12 de agosto de 2015.

MENEZES , Cinara. Ecos da escravidão. Carta Capital. 10/03/2011. Disponível em < http://www.cartacapital.com.br/politica/ecos-da-escravidao-2> acesso em: 04 de outubro de 2014.

MOURA, Clóvis. A história do negro brasileiro. São Paulo: Ática, 1989.

PASSOS, Walter. A maldição de Cam - mentiras para escravizar e explorar o povo preto. Disponível em: < http://cnncba.blogspot.com.br/2008/03/maldio-de-cammentiras-para-escravizar.html> acesso em: 05 de junho de 2014.

ROCHA, Edmar José; ROSEMBERG, Fúlvia. Autodeclaração de cor e/ou raça entre escolares paulistanos(as). Disponível em <

http://www.academia.edu/740031/Autodeclara\%C3\%A7\%C3\%A3o_de_cor_e_ou_ra $\% \mathrm{C} 3 \% \mathrm{~A} 7 \mathrm{a} \_$entre_escolares_paulistanos_as_> Acesso em: 13 de janeiro de 2015.

UCHOA, Pablo. Brasil dominou tráfico de escravos no mundo. Disponível em: $<$ http://www.bbc.com/portuguese/reporterbbc/story/2007/04/070405_escravos_datab ase_pu.shtml> Acesso em: 22 de outubro de 2014. 